Infusion Therapy

Transfusion Medicine

Infusionstherapie

Transfusionsmedizin
Clinical Information · Klinische Information

Infus Ther Transfus Med 2000;27:226-234
Received: J uly 25, 2000

Accepted: August 23, 2000

\title{
Hepatitis B Virus
}

\author{
Arbeitskreis Blut, Untergruppe «Bewertung Blutassoziierter Krankheitserreger»
}

\section{Current Knowledge about the Pathogen}

\subsection{Characteristics of H epatitis B Virus}

$\mathrm{H}$ epatitis B virus (H BV) is the prototype of the Hepadnaviridae family of viruses (genus 0 rthohepadnaviridae). Similar viruses are found in primates, woodchucks and ground squirrels, and some that are distantly related (genus A vihepadnaviridae) in various bird species. A II members of this family of viruses are hepatotropic, noncytopathogenic and very species-specific. They cause persistent infections with hightiter viremia. Orthohepadnaviridae can cause acute and chronic hepatitis as well as hepatocellular carcinoma.

H BV is a spherical particle with a diameter of between 42 and $45 \mathrm{~nm}$. It consists of an icosahedral nucleocapsid (the core) and an outer shell made up of lipids and proteins. H epatitis $B$ surface antigen ( $\mathrm{HBSA} \mathrm{g}$ ) is the main antigen of the viral envelope. It is made up of small ( $\mathrm{SHBS}$ ), medium (MHBs) and large (LHBS) HBs protein with the domains $S$, preS2 and pres1 (fig. 1).

In addition to the virions, the blood of infected individuals also contains spherical and filamentous HBs particles with a diameter of $22 \mathrm{~nm}$ and without nucleocapsid. These occur in numbers approximately 1,000 times greater than the number of virions.

The nucleocapsid is formed by $\mathrm{HBCA}$ g. In addition to viral D NA, this 'core particle' contains an HBV-specific D NA polymerase and a host-coded protein kinase. $A$ soluble form of $\mathrm{HBCA} g$ released into the plasma is known as the $\mathrm{H} B$ e antigen (HBeA g).

H BV occurs in at least 7 genotypes $(A-G)$ the distribution of which varies according to geographic region. The $S$ domain of $\mathrm{HBSA} g$ also has the subtype $d$ or $y$ and w1-4 or $r$ determinants. In patients with high-titer viremia, the variability of $\mathrm{HBV}$ is not particularly great, but increases under immunoselection.

The virus genome is a circular, partially double-stranded D NA molecule made up of around 3,200 bases. $A$ t the 5 ' end of the coding strand (minus strand), it contains covalently bound viral DNA polymerase as a protein primer for DNA synthesis, with an RNA primer at the $5^{\prime}$ end of the plus strand. The minus strand is synthesized by reverse transcription of the pregenomic HBV R NA.

$\mathrm{HBV}$ can be inactivated by lipid-dissolving organic solvents or by temperatures exceeding $60^{\circ} \mathrm{C}$. Because the proteins in the viral envelope are covalently bonded and contain relatively little lipid, HBV is more stable than other enveloped viruses $[1,2]$.

\subsection{Infection and Infectious D iseases}

Wild-type HBV has not been shown to induce direct cytopathogenic effects similar to those seen in other viruses although particular variants seem to possess a certain degree of pathogenicity. Pathogenesis is largely determined by the immune reactions of the infected host. In individuals with immune suppression or undeveloped immune systems, the virus replicates rapidly without major symptoms.

In the plasma of immunotolerant carriers of the virus, HBV typically generates particle counts of $10^{9}$ to $10^{10} / \mathrm{ml}$ [3] although not all particles are infectious. The infectivity titers found in the plasma of chimpanzees following intravenous administration are typically around $10^{8} / \mathrm{ml}$. HBV can be transmitted in saliva, tears, breast milk, vaginal secretions, sperm, and ascitic fluid. The virus is transmitted most effectively via the intravenous route although it can be transmitted percutaneously or by contact of mucous membranes with fluid containing H BV. There are many H BV carriers who have particle titers of less than $10^{6} / \mathrm{ml}$ and are very unlikely to infect those around them [4].

The number of $\mathrm{HBV}$ particles is normally measured in terms of the number of HBV DNA molecules (genome equivalents) [3]. M easurement of the number of infectious particles is impracticable because HBV only replicates in vivo or in differentiated primary human or chimpanzee hepatocytes. The mechanism whereby the virus is taken up by the liver cells and possibly other cells (white blood cells) remains unclear.

In adults with a competent immune system, a low infectious dose generally results in asymptomatic infection and the development of immunity. Higher doses, e.g. from percutaneous inoculation with high-titer blood (serum), causes acute hepati-

\begin{tabular}{ll}
\hline KARGER & $\odot$ 2000 S. K arger G mbH , Freiburg \\
Fax +4976145207 14 & A ccessible online at: \\
$\begin{array}{l}\text { E-mail Information@K arger.de } \\
\text { www.karger.com }\end{array}$ & www.karger.com/journals/iut
\end{tabular}



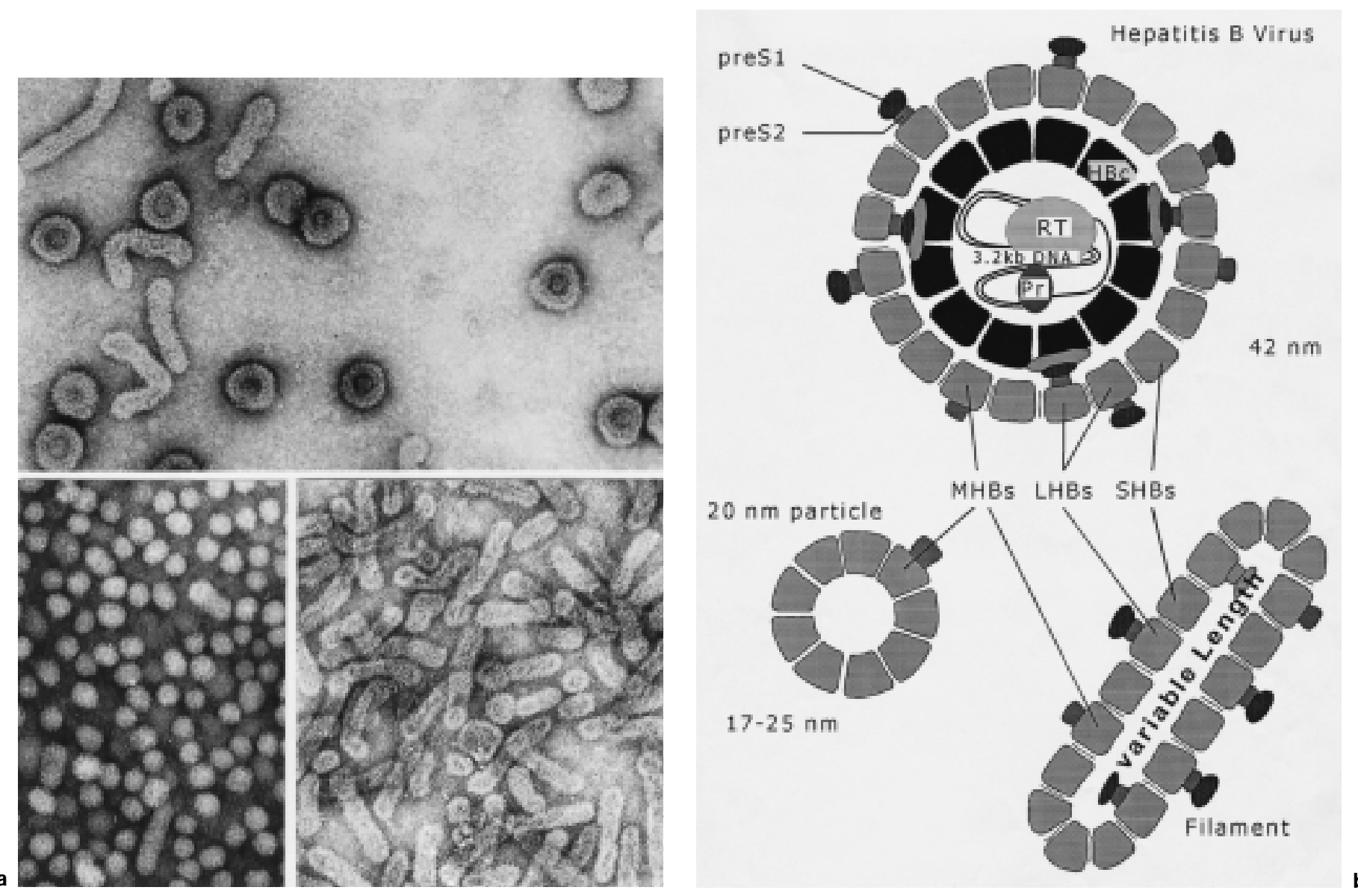

Fig. 1. a E lectron micrograph (negative contrast) of hepatitis $B$ virus particles (top), filamentous (bottom, right) and spherical (bottom, left) $H B s A g$ particles. b M odel representation of the particle structure and the viral surface proteins (L H B s, M H Bs, SH Bs) with the S, PreS1 and PreS2 domains. Inside the virus particle can be found the core protein $(H B C)$, the viral DNA and the virus-coded polymerase with reverse transcriptase (RT) and protein primer (PR) domains.

tis $B$ from which the victim usually recovers. The incubation time for HBV to the onset of clinical symptoms is generally between 45 and 180 days, depending on infectious dose and port of entry. During the prodromal phase of up to 4 weeks before the onset of clinical disease with jaundice, flu-like symptoms are common, with varying occurrences of itching, rash and joint pain, most likely the result of immunocomplex formation. Fulminant hepatitis or fatal liver failure are rare $(<0.1 \%)$ and are usually caused by infection with $\mathrm{HB} \mathrm{e-nega-}$ tive $H B V$ variants or secondary infection with hepatitis $D$ virus (HDV).

$5-10 \%$ of all patients with acute hepatitis B develop chronic hepatitis. In contrast, when neonates and immunocompromised individuals become infected, they almost always develop subclinical, persistent infection with partial immune tolerance and high-titer viremia. A certain proportion of immunocompetent adults, however, also develop persistent H BV infection with no overt symptoms of hepatitis.

With increasing age, persistent infection often develops into chronic hepatitis and can lead to cirrhosis of the liver and hepatocellular carcinoma. Pathogenesis is determined by the cy- totoxic immune response to $\mathrm{HBV}$ antigens which is present but not sufficient to eliminate the virus. The ongoing process of liver cell destruction leads to frequent cell divisions and an increased incidence of mutations. Fibrosis of the liver tissue is also induced. In rare cases, life-threatening immunocomplex diseases such as polyarteritis nodosa or glomerulonephritis may also develop $[4,5]$.

\subsection{E pidemiology}

Incidences of acute hepatitis B per year and 100,000 inhabitants as reported in the literature are given in table 1.

B ecause not all diseases are reported and symptomatic H BV infection only represents a proportion of all $\mathrm{HBV}$ infections, the figures quoted need to be multiplied by a factor of between 4 and 30, according to M eheus [6], in order to give a true picture of the incidence of infection in the different countries. In the U SA, for example, 25,000 new cases of H BV infection are reported per year. However, the real figure is thought to be around 300,000 new cases of infection per year. Worldwide, there are thought to be 300 million chronic H BV carriers and approximately 1 million deaths a year caused by 
H BV. In I taly, there are around 1.5 million chronically infected people and around 9,000 deaths per year caused by HBV. $H$ owever, the incidence has decreased in the last 20 years [7]. $\mathrm{O}$ the basis of the number of cases of $\mathrm{HBV}$ disease reported in Germany (around 6,000) and the acknowledged fact that not all cases are reported, a figure of between 14,000 and 27,000 cases of HBV disease and between 27,000 and 55,000 cases of H BV infection was arrived at 1993. The total number of chronic hepatitis B carriers in G ermany is currently around 500,000 . This corresponds to about $0.7 \%$ of the population (Jilg and Palitzsch, personal communication).

\subsection{D etection M ethods and Their Significance}

Screening for active H BV infection is now carried out routinely using the ELISA method to detect the presence of $\mathrm{HBSA} g$ in the serum or plasma. A fter the incubation period, both active and past infection can be detected by ELISA to screen for the antibody to the core antigen (anti-HBC). Anti-HBC is therefore the best indicator of the prevalence of $\mathrm{HBV}$ infection. Immunity to HBV acquired naturally or by immunization can be demonstrated by the presence of antibodies to HBsA g (anti-HB s) detected by means of E LISA.

Testing for viral nucleic acid, which is also helpful in answering some diagnostic questions, was originally carried out using various nucleic acid hybridization techniques. B ecause of their superior sensitivity, however, amplification techniques have in recent years become the method of choice in screening for viral D NA [8]. The diagnostic parameters characteristic of the various forms of $\mathrm{HBV}$ infection are shown in figure 2 and in table 2.

The test systems for detecting H B SA g currently licensed in G ermany have a detection limit of 0.01-1.0 Paul-E hrlich-Institut (PEI) units/ml. These figures are based on the standards introduced by the PEI in 1987 with the ad and ay HBsA g determinants. The WHO standard (WHO HBsA g ad) gives a detection limit of $0.005-0.05 \mathrm{IU} / \mathrm{ml}$ because the ratio of the two standards is approximately $1: 2$, i.e. $1 \mathrm{PEI}$ unit is equivalent to $0.5 \mathrm{IU}$. It is not possible to give a value for test sensitivity in $\mathrm{ng} / \mathrm{ml} \mathrm{H} \mathrm{B} \mathrm{sA} \mathrm{g} \mathrm{because} \mathrm{reference} \mathrm{preparations} \mathrm{labelled} \mathrm{in}$ $\mathrm{ng} \mathrm{H} \mathrm{B} \mathrm{sA} \mathrm{g/ml} \mathrm{[9]} \mathrm{are} \mathrm{no} \mathrm{longer} \mathrm{available.} \mathrm{A} \mathrm{ny} \mathrm{conversion} \mathrm{can}$ therefore be no more than a rough estimate (according to the PEI).

The HBsA g test will become positive about 6-8 weeks after infection. However, infectivity may be present before this. Jagodzinski et al. were able to detect viral DNA using PCR 14-35 days before positive identification of $\mathrm{HB} \mathrm{SA} \mathrm{g}$ [10].

HBV DNA testing can be used to quantify infectivity and is an important variable for monitoring treatment and disease progression.

Nucleic acid can sometimes be detected even after the infection has subsided and H B sA $g$ is no longer detectable or antiH Bs is present [11], however, it is not known whether such individuals are infectious.
Table 1. Incidences of acute hepatitis B per year and 100,000 inhabitants

\begin{tabular}{lc}
\hline USA & 10 \\
UK & $1-2$ \\
Sweden & 3 \\
Germany & 7 \\
E urope (according to the WH O) & 20 \\
\hline
\end{tabular}

Table 2. Diagnostic parameters during H BV infections ${ }^{a}$

\begin{tabular}{llll}
\hline & A cute & Chronic & Past \\
\hline HBV D NA & early+/late- & $+(-)$ & $-(+)$ \\
HBSA g & + & + & - \\
HBeA g & early +/late- & $+/-$ & - \\
A nti-H B I gM & ++ & $-/+$ & - \\
A nti-HBC total & + & + & $+(-)$ \\
A nti-HBe & early-/late+ & $-/+$ & $-/(+)$ \\
A nti-HBs & - & $-(+)$ & $+(-)$ \\
A LT & +++ & + alternating- \\
\hline
\end{tabular}

aR are findings in brackets.

\section{Blood and Plasma Donors}

\subsection{Prevalence and Incidence in B lood D onor Populations}

A ccording to a survey of $\mathrm{G}$ erman blood donation centers carried out by the PEI, 801 out of 4,246,906 donor samples tested positive for HBSA g. B ecause a sufficiently clear distinction was not made between first-time donors and regular donors, conclusions with regard to incidence and prevalence cannot be drawn on the basis of these data. When quoting prevalence rates, a distinction must be made between the prevalence of HBV carriers and the prevalence of people with a marker of past or current HBV infection. The former is determined by the HBSA g test carried out on blood donors, but a combination of the anti-H Bc test and the $\mathrm{H} \mathrm{B} \mathrm{sA} g$ test is required to determine the latter. B ecause HBsA g-positive donors are deferred, prevalence data based on H B sA g testing only apply to first-time donors.

The incidence data are more important. Testing repeat donors for $\mathrm{HBSA} g$ provides certain indicators as to the incidence of newly acquired $\mathrm{H} B V$ infection. These indicators are very inaccurate, however, because the presence of $\mathrm{HBsA} g$ in most infected people with fully functional immune systems is only transitory. On the basis of the known duration of HBs-antigenemia in people with spontaneously resolving acute hepatitis B, Schreiber et al. [12] came up with a correction factor of 2.4 which should be used to adjust for donors who have become H B sA g-negative. They thus obtained a calculated residual risk of $\mathrm{HB} \mathrm{BA}$ g-negative donor samples with $\mathrm{HBV}$ infectivity of 1:63,000 in the USA for the years 1991-1993. U sing a slightly modified calculation model, Stramer et al. [13] ob- 

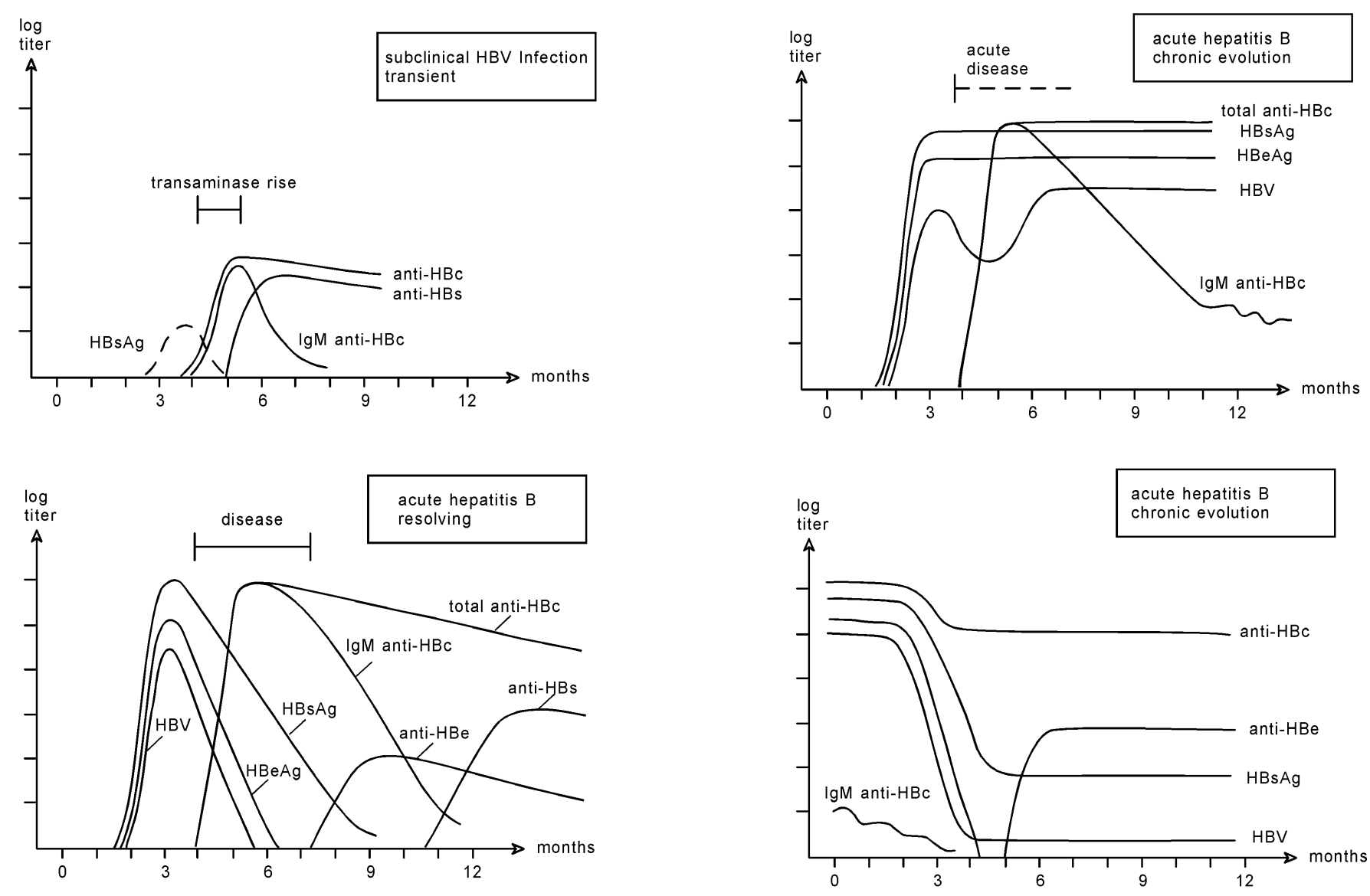

Fig. 2. Schematic diagram of viral serology in various forms of $H B V$ infection.

tained a figure of 1:77,500 for 1996/1997. In 1996, G lück et al. [14] found 43 cases of HBSA g seroconversions in a total of 2,850,820 donor samples. A ccording to Schreiber's calculation method, this gives a residual risk of 1:232,044 per donor. A ccording to similar estimates, the residual risk should be 1:112,000 in France [15] and 1:350,000 in A ustralia [16]. When considering the above estimates for HBV incidence in blood donors, it should be borne in mind that the period of detectable HBs antigenemia in infected but asymptomatic persons may well be much shorter, which means that the correction factor should be higher. The phase of actual infectivity may also be much shorter than is assumed. More accurate data could be obtained by recording values for anti-H B c seroconversion since this antibody is generally believed to persist for years and usually for life. H owever, the most recent findings suggest that, in infected individuals without any symptoms, transitory viremia (without $\mathrm{HBSAg}$ ) detectable by means of PCR often results in anti-H Bs rather than anti-H BC seroconversion (L efèvre, personal communication). H owever, anti-HBs is often undetectable following symptomatic infection, which is why it has never been used as a marker for prevalence and incidence. $A n$ accurate prospective picture of the incidence of HBV infection in blood donors could there- fore only be provided by the combined use of $\mathrm{HBSA} g, \mathrm{HBV}$ DNA , anti-H B c and anti-H Bs values.

The 3-5\% prevalence of anti-H BC among G erman $\mathrm{R}$ ed Cross (D R K ) donors calculated by Caspari et al. [17] indirectly suggests a considerably higher incidence of $\mathrm{HBV}$ infection. $\mathrm{O}$ n the basis of these figures, around 50,000-100,000 of the $2,000,000$ donors in Germany must have unwittingly become infected with HBV. If it is assumed that all these people became infected in adulthood, between the ages of 10 to 50 years, this would give an incidence of 1:200 to 1:2,000 per year for the last decade.

H owever, on the basis of the HB SA g test (with all the uncertainties mentioned) the incidence of $\mathrm{HBV}$ infection at DRK blood collection centers in 1997 was 1:43,478, and the prevalence of H BsA g carriers was 1:495. The corresponding figures in the USA were slightly higher for $\mathrm{HBSA} g$ incidence, at 1:26,316, but lower for H B sA g prevalence, at 1:730. A ccording to E uropean Plasma Fractionation A ssociation (EPFA) data, the incidence in various $E$ uropean countries on the basis of the H B sA g test is between 1:22,000 and 1:2,000,000. The residual risk which can be calculated from these figures depends on the interval between donations and the type of blood product. 


\subsection{D efinition of Exclusion Criteria}

In G ermany, the deferral of blood donors is governed by the guidelines of the Ä rztekammer (O rder of Physicians) and of the PEI. A ccording to current guidelines, people are deferred from donating blood for 5 years if they are shown to be infected with HBV or if they have had hepatitis B. Such people will then only become eligible to donate blood again if all virologic criteria indicate beyond all doubt that they are no longer contagious. The following combination of findings can be considered as a key criterion: HBSA g negative, serum glutamicpyruvic transaminase (SG PT; alanine aminotransferase, A LT) normal, HBV DNA with a sensitive NAT negative and $>100$ IU /I anti-HBs.

\subsection{D onor Testing and Significance}

Donor screening is governed by the guidelines mentioned under 2.2 .

According to these guidelines, each donation must be screened for H B sA g using an authorized test and must yield a negative result.

The concentration of SG PT must also be measured. The limit value of $45 \mathrm{U} / \mathrm{l}$ for women and $68 \mathrm{U} / \mathrm{l}$ for men must not be exceeded, as determined at $25^{\circ} \mathrm{C}$ using the optimized standard method from 1972.

The H B sA g screening method is a sensitive technique for detecting infectious donors.

In some countries, however not in Germany, it has long been established practice to carry out an additional screening test for anti-H B c-positive donors as a surrogate test for hepatitis C virus (HCV) and human immunodecifiency virus (HIV). With this test, it would theoretically be possible to identify those HBV carriers who are not/no longer HBsA g-positive. In fact, around $30 \%$ of people who test positive for anti-H BC alone are found to be H BV DNA -positive when highly sensitive detection methods are used. H owever, many of these people have other characteristics which would exclude them from donating blood (liver disease, H CV, HIV) [18]. Furthermore, blood from such individuals has only rarely been found to be infectious [19].

In G ermany, the introduction of anti- $\mathrm{H} \mathrm{Bc}$ testing is once again the subject of debate. In view of the existing requirement for people who have had acute hepatitis B to be deferred from donating blood for at least 5 years, we need to consider whether we should not also use $\mathrm{HBC}$ testing to screen for past $H B V$ infection which has gone unrecognized. However, in people who have had asymptomatic HBV infection, the degree and duration of $\mathrm{HBS}$ antigenemia and viremia are much lower, and infestation of the liver with latent H BV genomes is therefore also likely to be less extensive. These factors in turn determine the period of potential infectivity. Infections of this nature often fail to result in the formation of anti-HBC (see above).

A theoretical safety loophole also exists with regard to fresh frozen plasma which is stored in quarantine for 6 months. Sub- sequent testing for anti-HBC would probably detect $\mathrm{HBV}$ infection emergent during storage, whereas $\mathrm{HB}$ SA g testing probably would not. The extent to which the safety margin would be increased by anti-H Bc testing is not known, however, and may be very slight. The still relatively high nonspecificity of the tests is another argument against their introduction.

The introduction of HBV DNA screening with an appropriate method such as PCR in small pools or even for individual donations continues to be the subject of debate. This would enable $H B V$ variants with highly modified $H B S A$ g sequences to be detected in chronically infected donors [20,21]. A ccording to studies conducted by Schreiber et al. [12] and N übling [42], such methods could reduce the early diagnostic latency period before the appearance of $\mathrm{HBSA} g$ from a probably 57 to 32 days. It was shown, however, that the number of $\mathrm{HBV}$ genomes $/ \mathrm{ml}$ serum at this time is very low and that a sensitivity of 100 genomes/ml would be necessary to bring about a significant reduction in the diagnostic latency period. The late phase after the disappearance of $\mathrm{HBSA}$ g, when HBV carriers become HBsA g-negative, could only be detected with a very sensitive HBV DNA test method [12].

Experiments so far on around 3 million donor samples show that donors who are HBV DNA -positive but H B sA g-negative are very rare in $\mathrm{G}$ ermany [22]. The D R K blood collection service in North R hine-Westphalia found 16 out of 2 million H B SA g-negative donors to be positive for H BV DNA (detection limit: approximately $1,500 \mathrm{HBV}$ genomes $/ \mathrm{ml}$ ). In 5 of these cases, the findings were unclear. A nti-H Bs developed subsequently in 9 of these donors, but anti-H Bc only in $3 . \ln 2$ donors, anti-HBC and anti-HBs were positive from the start (L efèvre, personal communication).

It is possible that even more sensitive test methods would increase the number of positive blood donations. A quantitative WHO reference preparation for HBV DNA with a known number of $\mathrm{HBV}$ genomes/ml has been available since N ovember 1999. U nlike earlier ring trials [3, 23], the WH O ring trial with this material showed excellent qualitative and quantitative consistency with various methods of measurement (Saldanha, personal communication).

\subsection{D onor Interviews}

Paragraph 3 of the guideline for donor deferral as presented above prescribes a detailed inquiry of potential donors about their medical history (see 2.2).

\subsection{D onor I nformation and Counselling}

In accordance with the recommendations of the $\mathrm{G}$ erman $\mathrm{Ad}$ visory Committee B lood (A rbeitskreis B lut) [24, 25], if a sample is found to be positive for $\mathrm{HBSA} g$ in various test systems, a second sample should be obtained from the donor and examined. If the initial finding is confirmed or other evidence of the presence of $H B V$ infection is found $(\mathrm{HBeAg}$, anti-HBC, HBV DNA ), the donor and his/her family physician are informed of the results. The family physician is responsible for 
carrying out any further diagnostic tests and treating the patient. The donor is informed by the blood collection center in writing that he/she is ineligible for donating blood. Such a person only becomes eligible to donate blood again if he/she is found to have recovered from the infection, virologic criteria indicate beyond doubt that he/she is no longer contagious, and 5 years have elapsed since HBV infection was detected or since the patient recovered from hepatitis $B$ (see above).

\section{Recipients}

3.1 P revalence and Incidence of B lood-A ssociated Infections and Infectious D iseases in Recipient Populations

B etween 1995 and 1997, the PE I received 347 reports of H BV infection associated with the transfusion of blood components in which there was a suspicion that the infection may have been caused by the transfused preparation. In only 14 of these cases (4\%), a potentially infectious donor was identified by subsequent testing. A ccording to similar figures obtained as part of a step-wise plan for the years 1990-1995, HBV infection was diagnosed in 434 recipients of blood components, but an infected donor was only identified in 19 cases.

Of the 4,185 reported cases of transfusion-transmitted hepatitis B in England and Wales between 1991 and 1997, Soldan et al. [26] only found convincing evidence that infection had been transmitted by the donor in 24, i.e. in 1.4 per 1 million donations. Of the 14 donors identified, three were recently and 11 chronically infected. In most cases, it must be assumed that the recipient already had $\mathrm{HBV}$ infection or that another source of infection was involved. Whether the rate of $\mathrm{HBV}$ transmission was really as low as this or whether screening was inadequate cannot be established retrospectively.

A Iternatively, the residual risk can also be determined on the basis of the incidence of seroconversion and the duration of the diagnostic latency period although even these data are unreliable (see 2.1).

It is very rare for H B V to be transmitted by blood products. In 1994, there were 35 cases of H BV transmission in total in Germany linked to two batches of a coagulation factor. I dentification of the virus in both preparation and patients was achieved by sequencing. A n error in the heat inactivation process was identified as the source of product contamination. B ecause the virus load of the starting material for these batches was very low, the HBV DNA could only be identified confidently by PCR after enrichment. The virus was a typical wild type which would have had to be identifiable using the HBSA g test, assuming the detection limit was exceeded (Thomssen, personal communication).

\subsection{I mmune Status (R esistance, E xisting I mmunity, I mmune} Response, A ge, Exogenous Factors)

Generally speaking, after infection or immunization, anti-H Bs protects against disease or persistent infection. In people who are not immune, the infection follows the course described under $1.2[4,5]$. A Ithough there have been many reports of escape variants of $\mathrm{HBV}$ with highly modified $\mathrm{HBS}$ antigenicity in infected individuals, under coexisting anti-H Bs no signs of horizontal transmission have been observed [27].

Immunization of individuals who regularly receive blood and blood products has been recommended by the R obert Koch-Institut Standing Committee on Immunization (STIKO) [28]. The efficacy of immunization should be checked where there is a high risk of HBV infection. A booster should be given every 10 years or when the anti$\mathrm{HBs}$ titer falls below $50 \mathrm{IU} / \mathrm{l}$.

\subsection{Severity and Course of the $D$ isease}

The natural history of the disease is determined by the virus load, the route of transmission and the presence of any underlying disease or immune suppression.

The risk of developing chronic infection depends on age. Coinfection with HCV and H BV often leads to cirrhosis, liver failure, or liver cancer in the long term. When a child is infected at birth, the course is almost always chronic. The persistence rate gradually decreases during childhood, reaching around $5-10 \%$ by early adulthood. High-titer viremia and infection via the intravenous route more often result in persistence of the virus.

The development of severe late sequelae, usually in more advanced age, depends on interactions with other factors. In Germany, HBV carriers are estimated to have about a $10 \%$ risk of dying early from liver failure or liver cancer. A major problem is the risk of infection which carriers of the virus represent to others, particularly health care professionals.

Fulminant forms are generally rare but are more common in people co-infected with HDV or HCV. A cute infection with $\mathrm{HB}$ eA g-negative HBV variants is also sometimes associated with a higher incidence of fulminant hepatitis.

\subsection{Therapy and Prophylaxis}

Interferon alpha has been licensed for the treatment of chronic hepatitis B. It has a clear effect on viral replication as well as immunomodulatory effects. H owever, long-term effects with elimination of HBV DNA from the liver can only be shown in about one third of all treated patients.

0 ther therapeutic approaches include treatment with other immunomodulators, pres antigen-containing HBs vaccines, and cytokines. R esults with nucleoside analogues are very promising. O ne such agent is lamivudine which has already proved to be effective. This substance reduces the concentration of the HBV circulating in the blood, is well tolerated following oral administration and, in some cases, leads to disappearance of $\mathrm{H} \mathrm{B} \mathrm{eA} \mathrm{g.} \mathrm{In} \mathrm{most} \mathrm{cases,} \mathrm{however,} \mathrm{viremia} \mathrm{increas-}$ es again on discontinuation of therapy. Furthermore, as with all nucleoside analogues, resistance may develop [29]. D evelopment of resistance is even more common under treatment with famciclovir. 
The most important and successful preventive measure is still active immunization with $\mathrm{HBSA}$ g. A ccording to the STIKO recommendations of $M$ arch 1998, all neonates should receive their first immunization within the first 3 months of life. A II children aged between 11 and 18 years should also be immunized. STIKO also recommends immunization of high-risk groups of people, including 'patients who frequently receive blood and blood components (haemophilia) and patients due to undergo major surgery (e.g. operations involving extracorporeal circulation)' [28].

The introduction of H B V immunization in Taiwan has already led to a statistically significant reduction in the incidence of hepatocellular carcinoma in children [30]. O ne problem that remains with immunization is the number of nonresponders or low responders with $<10 \mathrm{IU} / \mathrm{I}$ anti-H Bs, which is particularly high among the elderly, the overweight, people who smoke and immunocompromised people.

Passive immunization with high-titer hepatitis B -specific immunoglobulin ( $\mathrm{HIG}$ ) is particularly useful for postexposure prophylaxis and in $\mathrm{HBV}$-infected liver transplant patients. STIKO specifically recommends passive/active immunization of babies born to HBsA g-positive mothers. Passive prophylaxis should always be combined with active immunization, except in immunocompromised patients.

\subsection{Transmissibility}

In the general community, the only way the virus can really be transmitted is by intimate contact, through spilt blood and skin injuries, but, above all, through sexual intercourse. For transmission to take place in this way, high virus titers of over $10^{6} / \mathrm{ml}$ are usually required. Such titers are generally only present in $\mathrm{HBeA}$ g-positive $\mathrm{HBV}$ carriers [31-33]. Where more major ports of entry are involved, e.g. during surgery, $\mathrm{HBV}$ can be transmitted by surgeons who are $\mathrm{HBV}$ carriers even if they have tested negative for $\mathrm{HBeAg}$ [32]. Even $5 \%$ of $\mathrm{H}$ B eA g-negative mothers transmit H BV to their babies. D uring blood transfusion, even very low virus titers can result in infection due to transmission of the virus via the intravenous route in very large volumes.

\subsection{Frequency of A dministration, Type and A mount of B lood Products}

B efore the introduction of a highly effective H B sA g screening method, almost all patients who needed frequent transfusions of blood products eventually became infected or developed immunity. Since the introduction of sensitive $\mathrm{HBSA} g$ tests in the 1970s, the number of HBV infections has decreased dramatically. A nother contribution to this reduction has been made by the viral inactivation of plasma protein preparations although this is difficult to validate for H BV and has failed in a few rare cases.

\section{Blood Products}

4.1 Infectious $L$ oad of the Starting $M$ aterial and Test $M$ ethods During the incubation period and in persistent HBV infections, over $10^{8}$ infectious particles/ml can be present in the blood. Under such circumstances, donors will be H B sA g-positive and will be detected by donor screening tests. In the early, H B sA g-negative phase, titers of $<10^{6} / \mathrm{ml}$ can be expected [10]. HBSA g variants which react negatively in the ELISA assay have been reported [20,21]. These are very rare and are of no relevance to the spread of $\mathrm{HBV}$ infection.

Testing individual donations for $\mathrm{HBSA} g$ and repeat testing of the plasma pool are stipulated as measures for preventing contamination of the starting material for plasma derivatives with HBV. M anufacturer testing of the plasma pool is repeated in an independent test laboratory for every preparation as part of the batch testing process. A s a result of these measures, the National Institute of Biological Standardization and Control found HBSA g in 9 out of 9,300 plasma pools between 1986 and 1994 and did not release the preparations [34]. The discrepancy between the negative test results yielded initially by the individual donor sample and positive testing in the highly diluted pool was attributable to the use of better methods for subsequent testing. Between 1994 and M ay 1999, H B sA g has not been detected in any of the 16,851 plasma pools tested by the PEI.

In the last 3 years, $\mathrm{H} \mathrm{B} \mathrm{sA} g$ has been identified in $0.2 \%$ of firsttime donors but only $0.02 \%$ of repeat DRK donors in North R hine-Westphalia (see above). O verall, the residual risk of HBV transmission in blood or blood components is not known exactly but is probably very low.

\subsection{M ethods for R emoval and I nactivation of the Infectious A gent}

HBV is a highly stable infectious pathogen which can only be removed using special methods. Various heat treatments (such as pasteurization for $10 \mathrm{~h}$ at $60{ }^{\circ} \mathrm{C}$ ), the solvent-detergent technique, and inactivation with $\beta$-propiolactone are used during the manufacture of plasma derivatives. The solvent-detergent technique causes disintegration of the lipid envelope as well as inactivation of H BV [35]. A ccording to a study conducted by Wieding et al. [36], the solvent-detergent technique is capable of reducing the infectivity of a solution containing HBV by more than $10^{5}-10^{6}$ chimpanzee-infective doses (CID ). O $n$ the basis of clinical experience, we can assume that the other methods are also capable of inactivating HBV effectively. B ecause of the difficulty of validating H BV inactivation, the HBV load of a plasma pool used for the manufacture of plasma protein preparations should not exceed a value of $100 \mathrm{HBV}$ particles $/ \mathrm{ml}$, provided that appropriate tests for HBV DNA are carried out. 
A Ithough H BV can be removed by filtration, meticulous control and examination is required because the effectiveness of this method is highly dependent upon the type of filter used and the filtration conditions. Filtration is currently used as an adjunct to other measures.

In the case of cellular blood components, inactivation is not yet possible although various methods are presently being studied [37-39].

\subsection{Feasibility and Validation of Procedures for Removal/ Inactivation of the Infectious A gent}

It is not yet possible to test the efficacy of methods for removing or inactivating H BV. There is still no suitable growth system available which could be used for such tests. HBV infection of primary human hepatocyte cultures in vitro is defective. Which model viruses would be suitable for HBV also remains unknown. The E uropean guideline on viral inactivation states accordingly that no practicable test system exists for $\mathrm{HBV}$ validation studies [40].

The duck HBV (DHBV) and the woodchuck HBV (WHV) have been suggested as model viruses for $\mathrm{HBV}$. WHV is very similar to H BV, but the woodchuck is generally too expensive as an animal model for the validation of viral inactivation techniques. The DHBV can be grown in embryonated duck eggs or in primary duck hepatocytes and titrated although this at least requires D H BV -free ducks to be kept [41]. D H BV resembles HBV in its genomic organization and replication strategy. However, the two viruses differ greatly in terms of primary protein structure and transmission routes. For example, D HBV is almost always transmitted vertically and its envelope proteins contain no stabilizing disulphide bridges. $G$ reat caution should therefore be exercised when extrapolating data from D HBV to HBV.

Q uantitative PCR testing for HBV DNA can be helpful for validating physical viral removal (e.g. by nanofiltration or precipitation) and inactivation methods which destroy DNA. O n the other hand, although the infectivity of $\mathrm{HBV}$ is destroyed by pasteurization or solvent-detergent treatment, HBV genomes can still be detected by means of PCR in products subjected to such treatments. The meaningfulness of such tests in relation to the reduction in the risk of infection is therefore not clear in the case of some methods.

\section{Assessment}

B ecause of the large number of chronic carriers and the considerable influx of population groups with a high H BV prevalence, HBV continues to be a major problem for health care policy in Germany, particularly as it is difficult to prevent transmission via sexual intercourse and other forms of intimate contact. A lthough the program to immunize children which has recently begun on a worldwide scale may eradicate $\mathrm{HBV}$ in the long term, this will still take many years. Until then, reliable methods of preventing HBV transmission by blood products will remain necessary because the consequences of infection are often very serious and no permanently effective treatment is foreseeable.

The highly sensitive H B sA g screening methods currently employed are capable of reliably identifying donors who are HBV carriers. H B SA g-negative variants of H BV have not yet been seen to present a major problem. Plasma derivatives which have been manufactured properly can be considered safe as far as HBV is concerned. A ccording to current estimates, the residual risk of $\mathrm{HBV}$ transmission through noninactivated blood products from donations of $\mathrm{G}$ erman origin is less than 1:100,000. The voluntary testing for HBV DNA by means of nucleic acid amplification performed at some blood collection centers has resulted in the identification of only very few additional HBV-positive donors of whole blood. Consequently, nucleic acid amplification testing of individual donations of cellular products would not appear to be urgently required. It could, however, be useful for testing plasma pools. Screening donors for anti-HBC may also lead to the identification of a few additional HBV carriers, but no figures are available for this. Indirect epidemiological evidence suggests that most asymptomatic HBV infections are not associated with virus titers which would have an impact on blood donation. In view of these findings, the introduction of $\mathrm{HBC}$ testing does not seem to be necessary. A useful measure from the point of view of health care policy would be to offer all blood and plasma donors immunization against hepatitis $B$. This would largely prevent donors from becoming infected with H BV in the first place, would obviate the need for expensive additional screening measures and would benefit the donors themselves.

This paper was completed on September 22, 1999, and approved by the German A dvisory Committee Blood (A rbeitskreis Blut) on November 16,1999 . It was compiled by the members of the subgroup 'A ssessment of Pathogens Transmissible by Blood' of the German A dvisory Committee Blood (A rbeitskreis B lut):

Prof. D r. R einhard B urger

Prof. Dr. Wolfram Gerlich

Prof. D r. Lutz G ürtler

Dr. M argarethe $\mathrm{H}$ eiden

Dr. Walter Hitzler

Prof. D r. Bernd Jansen

Prof. D r. Volker K retschmer

Dr. Hans L efèvre

Prof. D r. Johannes Löwer

Prof. Dr. Wolf-D ieter Ludwig

Dr. Thomas M ontag-L essing

PD D r. R ainer Neumann

D r. A rnold Paessens

Prof. D r. Georg Pauli

Prof. D r. R ainer Seitz

Dipl. M ed. U we Schlenkrich,

Dr. Edgar Werner

Dr. H annelore Willkommen 


\section{References}

$1 \mathrm{G}$ anem D: Hepadnaviridae: The viruses and their replication; in Fields $B N$, K nipe DM, H owley PM (eds): Fundamental V irology, 3rd ed. Philadelphia, Lippincott R aven, 1996 pp 2703-2737.

2 Kann M, Gerlich WH: Hepatitis B; in Topley \& Wilson's Microbiology and Microbial Infections, vol 1 Virology, 9th ed. London, A rnold, 1998, pp 745-773.

3 Hermann K H, Gerlich WH, Chudy M, Schaefer S, Thomssen $\mathrm{R}$, E urohep Pathobiology $\mathrm{G}$ roup: Q uantitative determination of hepatitis $B$ virus $D N A$ in two international reference plasmas. J Clin M icrobiol 1999;37:68-73.

4 Hollinger FB: Hepatitis B virus; in Fields BN, K nipe D M, H owley PM (eds): Fundamental Virology, 3rd ed. Philadelphia, Lippincott R aven, 1996, pp 2738-2808.

5 Dusheiko G : Hepatitis B; in Bircher J et al (eds): Oxford Textbook of Clinical H epatology, vol 1, 2nd ed. Oxford, Oxford M edical Publications, 1999, pp 876-896.

6 M eheus A : R isk of hepatitis $A$ in adolescence and young adulthood. Vaccine 1995;13(suppl 1):31-34.

7 Crovari P: Epidemiology of viral hepatitis $B$ in I taly. Vaccine 1995;13(suppl 1):26-30.

8 Gerlich WH, Thomssen R: Structure, replication and laboratory diagnosis of hepatitis virus; in Bircher J et al (eds): Oxford Textbook of Clinical H epatology, vol 1, 2nd ed. Oxford, O xford Medical Publications, 1999, pp 828-870.

9 Gerlich WH, Thomssen R : Standardized detection of hepatitis B surface antigen: D etermination of its serum concentration in weight units per volume. Dev B iol Standard 1975;30:78-87.

10 Jagodzinski $L, K$ raus $F, G$ arett $P$, Schumacher $R$, $M$ anak $M$ : $D$ etection of hepatitis $B$ viral sequences in early H BV infection. Transfusion 1994;34:37.

11 R ehermann B, Ferrari C, Pasquinelli C, Chisari FV: The hepatitis $B$ virus persists for decades after patient's recovery from acute viral hepatitis despite active maintenance of a cytotoxic T-lymphocyte response. $N$ at M ed 1996;2:1104-1108.

12 Schreiber GB, Busch M P, K leinman SH, Korelitz $\mathrm{JJ}$ : The risk of transfusion-transmitted viral infections. N Engl J Med 1996;334:1685-1690.

13 Stramer SL, A berle-G rasse J, D odd RY: HIV, HBV and $\mathrm{HCV}$ incidence and prevalence rates in US whole blood donors. Transfusion 1998;38(suppl): $81 \mathrm{~S}$

14 G lück D, Kubanek B, M aurer C, Petersen N : Seroconversion of HIV, HCV and HBV in blood donors in 1998 - R isk of transmission by blood products in Germany. Infusionsther Transfusionsmed 1998;25: 82-84.
15 Courouce A M, Pillonel J: E stimation du risque de transmission des virus des hepatitis $B$ et $C$ et des retrovirus humains par transfusion de derives sanguins labiles. Transfus Clin B iol 1996;1:13-18.

16 Whyte GS, Savoia HF: The risk of transmitting HCV, HBV or HIV by blood transfusion in Victoria. Med J A ust 1997;166:584-586

17 Caspari G, B eyer HJ, Elbert G, Koerner K, M uss P Schunter FW, Uy A, Gerlich W, Thomssen, R Schmitt $\mathrm{H}$ : U nsatisfactory specificity and sensitivity of six enzyme immunoassays for antibodies to hepatitis B core antigen. J Clin Microbiol 1989;27: 2067-2072.

18 Jilg W: Individuals with antibodies against hepatitis $B$ core antigen as the only serological marker for hepatitis $B$ infection: $\mathrm{H}$ igh percentage of carriers of H epatitis B and C virus. J H epatol 1995;23:14-20.

19 Saraswat S, B anerjee K, Chaudhury N, M ahant T, K handekar P, G upta R K, Naik S: Post-transfusion hepatitis type $B$ following multiple transfusions of HBsA g-negative blood.J H epatol 1996;25:639-643.

20 Jongerius J $M$, Wester $M$, Cuypers $H T$, van O ostendorp WR, L elie PN, van der Poel CL, van L eeuwen E F : N ew hepatitis $B$ virus mutant form in a blood donor that is undetectable in several hepatitis $B$ surface antigen screening assays. Transfusion 1998; 38:56-59.

21 G rethe S, M onazahian M , Thomssen R : Characterization of unusual escape variants of hepatitis $B$ virus isolated from a hepatitis $B$ surface antigennegative subject. J V irol 1998;72:7692-7696.

22 Caspari G, G erlich WH: H ighly sensitive detection of virus genomes in transfusion medicine. Infusionsther Transfusionsmed 1998;25:74-81.

23 Quint WG V, H eijtink R A, Schirm J, Gerlich WH, Niesters H G M : R eliability of methods for hepatitis B virus DNA detection. J Clin Microbiol 1995;33: 225-228.

24 Empfehlungen der A d-hoc-Kommission des A r beitskreises $B$ lut zum Rückverfolgungsverfahren (look back) für E inzelspender- und K leinpool-Blutpräparate. Bundesgesundheitsblatt 1994, pp 513514

25 Empfehlungen zum Vorgehen bei reaktiven Screeningtesten auf HIV- oder HCV-A ntikörper bzw. HBV-surface-A ntigen bei Blut- und Plasmaspenden. Bundesgesundheitsblatt 1995, 369-372.

26 Soldan K, R amsay M, Collins M : A cute hepatitis B infection associated with blood transfusion in $\mathrm{Eng}$ land and Wales, 1991-7: R eview of database. BM J 1999;318:7176-7195

27 Wilson J N, Nokes DJ, Carman WF: Current status of $\mathrm{HBV}$ vaccine escape variants - a mathematical model of their epidemiology. J Viral Hepat 1998;5 (suppl 2):25-30.
28 Mitteilungen der Ständigen Impfkommission am R obert Koch-Institut (1998): E mpfehlungen. Stand: M ärz 1998. E pidemiol Bull 1998:15:191-192.

29 Lai CL, Chien R N, Leung NW, Chang TT, G uan R, Tai DI, Ng KY, Wu PC, Dent JC, Barber J, Stephenson SL, Gray DF: A one-year trial of lamivudine for chronic hepatitis B. A sia $\mathrm{H}$ epatitis Lamivudine Study Group. N Engl J M ed 1998;339: 61-68.

30 Chang $\mathrm{MH}$, Chen $\mathrm{CJ}$, Lai MS, H su HM, Wu TC, Kong M S, Liang DC, Shau WY, Chen DS: U niversal hepatitis $B$ vaccination in Taiwan and the incidence of hepatocellular carcinoma in children. Taiwan Childhood H epatoma Study Group. N Engl J M ed 1997:336:1855-1859.

31 R epp R, Seuchter C, B reitbach B, L ampert F, Gerlich WH: R isk of hepatitis $B$ virus transmission in school. Lancet 1994:344:960-961.

32 Heptonstall J: Transmission of hepatitis B to patients from four infected surgeons without hepatitis Be antigen. N Engl J M ed 1997;336:178.

33 Caspari G, Gerlich WH: Mandatory hepatitis B virus testing for doctors. $L$ ancet 1998;352:991.

34 Ferguson M, M inor PD, G arrett A J, Page M, Thorpe $R, B$ arrowcliffe $T$ : Testing plasma pools for markers of viral contamination: the U K experience. Vox Sang 1996:71:21-26.

35 H orowitz B, Lazo A, G rossberg H, Page G, Lippin $A$, Swan $G$ : V irus inactivation by solvent/detergent treatment and the manufacture of SD -plasma. Vox Sang 1998;74(suppl 1):203-206.

36 Wieding J U, H ellstern P, K öhler M : I nactivation of viruses in fresh-frozen plasma. Ann Hematol 1993;67:259-266

37 Sloand E M : Viral risks associated with blood transfusion. Photochem Photobiol 1997;65:1685

38 Chin S, J in R, Wang X L, H amman J, M arx G, M ou $X, A$ ndersson I, Lindquist $L O, H$ orowitz $B$ : V irucidal treatment of blood protein products with UVC radiation. Photochem Photobiol 1997;65:432-435.

39 E ble BE, Corash L: Photochemical inactivation of duck hepatitis $B$ virus in human platelet concentrates: a model of surrogate human hepatitis B virus infectivity Transfusion 1996:36:406-418.

40 CPM P: BWP/269 1995;95:15.

41 D eva A K, Vickery K, Zou J, West RH, Harris J : E stablishment of an in-use testing method for evaluating disinfection of surgical instruments using the duck hepatitis B model. J H osp Infect 1996;33:119130

42 N übling $M$ : H öhere Sicherheit durch verkleinertes diagnostisches Fenster, Nukleinsäure-A mplifikationstechnik im Blutspendewesen. Diagn Dialog 1999:4-6. 